\title{
FALSOS AMIGOS, FALSOS COGNATOS, HETEROSSEMANTICOS: UMA SIMPLES ESCOLHA DE DESIGNAÇÕES?
}

\author{
Félix Bugueño Miranda
}

\begin{abstract}
RESUMO:The false friends dictionary is one of the most interestings developments in the history of the modern lexicography. Althought there is an agreement with the conceptual definition of this lexical phenomenon, the specialized literature uses several unclear designations for this "fait lexique".

This paper aims to show that "false friends" is the only free of contradiction designation for this lexicological matter.
\end{abstract}

PALAVRAS-CHAVES: lexicografia contrastiva, designações, falsos amigos.

\section{CONSIDERAÇÕES GERAIS}

Dentre as práticas lexicográficas da contemporaneidade ${ }^{1}$, uma das

Félix Bugueño Miranda é professor Visitante de Língua Espanhola, Departamento de Letras e Artes/Universidade Estadual de Santa Cruz, Ilhéus (BA). Dr.Phil.Rom, Universidade de Heidelberg/RFA

${ }^{1} \mathrm{~A}$ práxis de elaborar listas de palavras segundo diferentes critérios e objetivos é, porém, bastante antiga. Segundo HOMBURGER les plus ancienes glossaires connus sont ceux quel'on a retrouvés dans les documents sumériens et qui semblant avoir été destinés à des éleves à initier aux rites $(1951, \mathrm{p} .78)$. 
mais interessantes tem sido a daqueles dicionários bilingües ${ }^{2}$ que não se preocupam do conjunto léxico "in extenso"3 entre duas línguas, mas daquelas palavras que conformam um conjunto de "interseção léxica" entre essas duas línguas, por "soarem" parecidas ou iguais ou por se escreverem de maneira parecida ou igual.

Desde uma perspectiva metodológica, a discussão em torno desse fenômeno léxico se abre, junto com a questão central sobre que critério ou critérios resulta(m) relevante(s) para decidir quando é que efetivamente ocorre tal fato léxico, com uma outra questão pouco tratada. Até agora a discussão metalexicográfica se tem concentrado na "definição conceitual" desse fenômeno léxico. No entanto, existe uma variedade de designações para esse fenômeno, as quais, porém, são ambiguas e enganosas e terminam comprometendo até a coerência nas decisões macroestruturais.

O nosso objetivo no presente trabalho é discutir essas designações, mostrando que não é indiferente usá-las indistintamente.

Estamos em presença, então, de uma situação curiosa. Existe um consenso sobre a natureza do fenômeno léxico dos falsos amigos (no nível conceitual, v. 2. no presente trabalho); a(s) sua(s) designação(ões), porém, não são suficientemente "transparente(s)". O paradoxo é que, no plano teórico, o tratamento do problema deveria ser exclusivamente onomasiológico, mas, na prática, para poder ajustar a definição conceitual à designação não é possível fugir de considerações semasiológicas ${ }^{4}$, devido justamente a que carecemos de uma instância normativa que "de auctoritate" possa sancionar qual designação é lícita e qual não.

\section{SOBRE SISTEMAS CONCEITUAIS E DESIGNAÇÕES}

O léxico próprio de uma ciência, o tecnolecto, se forja de duas maneiras. Ora através de uma longa tradição no cultivo dessa ciência, ora através de uma tarefa normativa a cargo de alguma corporação ou grupo de trabalho "ad hoc".

$\mathrm{Na}$ segunda dessas possibilidades estamos frente a uma tarefa terminológica "ex professo". Exemplo paradigmático desse fazer é a

${ }^{2}$ Para um panorama do desenvolvimento da lexicografia bilingüe, cfr. BUGUEÑO (2000a, pp.123-124).

${ }^{3}$ A expressão "in extenso" deve ser entendida "lato sensu". Para nada estamos considerando coordenadas macroestruturais.

${ }^{4}$ É sempre bom manter bem clara a distinção entre definição conceitual e definição semasiológica, pelas conseqüências que isso tem. A definição conceitual pertence ao âmbito do "außereinzelsprachlich" (BALDINGER, 1977). V. nossas observações ao respeito em BUGUEÑO (2000c, p. 210). 
"Nomina Anatomica" (NA), criada para permitir uma univocidade entre um corpus de termos ${ }^{5}$ e os seus respectivos referentes. Naturalmente, uma tarefa assim exige que primeiro se construa um sistema conceitual que "segmente" de maneira clara, coerente e unívoca o objeto a fixar terminologicamente 6 . Em outras palavras, se trata de "dividir o mundo"" de uma forma "sui generis" ${ }^{8}$. Estamos, diante, por tanto, de um instrumento metodológico rigoroso que auxilia na hora de ter que trabalhar no âmbito de uma ciência. Nessas condições, é perfeitamente possível a coexistência de mais de uma designação para um mesmo conteúdo conceitual ${ }^{9}$. A única exigência é que as designações sejam previamente bem estabelecidas (fixadas). Um exemplo da coexistência de duas designações para um mesmo conceito é o caso do al. Lautlehre/Phonetik.

No entanto, existe uma segunda forma de se estabelecer designações para um mesmo conceito. Neste caso, porém, não se trata "stricto sensu" de uma instância institucional cuja tarefa seja, prioritariamente, desenhar um sistema conceitual e as suas respectivas designações. Concretamente, estamos falando da atividade implicitamente terminológica exercida, para as ciências da linguagem, por gramáticos, filólogos ou corporações que se preocupam das diferentes línguas. Para o caso específico da língua espanhola, pode-se falar de uma tarefa terminológica desde NEBRIJA (1492 [1992] $)^{10}$, ainda que, naturalmente, as designações para muitas das categorias gramaticais tenham mudado com o tempo. A tarefa começada por NEBRIJA (1492) proseguiu no espírito da Gramática de la lengua española (1771), publicada pela Real Academia Española (RAE). Essa tradição de estudos da linguagem tem sido, por tanto, fonte da terminologia gramatical de uso na lingüística hispânica. Esse trabalho, por outro lado, tem sido complementado com "iniciativas privadas", tais como a importantíssima contribuição de BELLO (1846 [1984]). Emfim, o peso dessas autoridades tem permitido a geração de uma terminologia gramatical bastante coerente para descrever a estrutura gramatical da língua espa-

\footnotetext{
${ }^{5}$ Definimos termo segundo REY: um nom definissable à líntérieur d'um systèm cohérent, énumeratif et/ou structuré (...) (1979, p.22)

${ }^{6}$ Um exemplo é o já clássico trabalho de HEGER (1964), onde se coloca claramente a necessidade de uma relação "um a um" entre conceito e designação. Mais modernamente, ainda que com um espírito "panrromânico" deve ter se em conta VERNAY (1991 e ss.)

${ }^{7}$ Ao falarmos em "dividir o mundo" estamos pensando em uma segmentação com critérios científicos, não na segmentação feita por toda língua natural (cfr. BUGUEÑO 2000d).

${ }^{8}$ ALMEIDA (1998, p.230), por exemplo, tem sido bastante acertado ao afirmar que a configuração dos sistemas conceituais com suas complexas relações está em função do objetivo que se propõe a análise conceitual.

${ }^{9}$ Ainda que, voltamos a insistir, a relação "ideal" é uma única designação para um conceito. ${ }^{10} U m$ panorama sobre a "consciência lingüística" respeito da língua espanhola durante o século XVI pode achar-se em BUGUEÑO (2000d).
} 
nhola. Assim, para o tempo que expressa uma ação já acabada antes do momento da elocução ${ }^{11}$, o espanhol oferece as seguintes designações: pretérito indefinido (GRAMÁTICA, 1931, § 93.), pretérito perfecto simple (ESBOZO, 1973, § 2.11.3.B.), pretérito (BELLO (1846 [1984, § 624]) ou pretérito perfecto absoluto (GILI GAYA, 1979, § 122.).

\section{A DEFINIÇAO CONCEITUAL DE UM FENÔMENO LÉXICO}

Nos dois casos analisados até agora, tanto nos "corpora" designativos forjados "ad hoc"12 como nas múltiplas designações forjadas "de facto", estamos, por um lado, frente a um padrão de regularidade na definição conceitual, e, por outro, frente a designações claras.

Já no âmbito da lexicografia contrastiva que nos preocupa nesta ocasião, se produz um fato curioso: até agora as ciências da linguagem não se têm preocupado de elaborar um Begriffsystem (HALLIG, WARTBURG, 1963), mas existe "de facto" um concenso sobre o que é o fenômeno léxico de duas palavras que pertencem a línguas diferentes, que possuem idêntica ou similar estrutura fonológica (ou gráfica) e que apresentam uma (ou mais) significações ${ }^{13}$ diferentes. Assim, por exemplo, METZLER (2000) define esse fenômeno como (...) morphol. und idiom. Entsprechungen zwischen zwei Spr., wenn sich zwei Wörter oder Wendungen scheinbar entsprechen, aber unterschiedl. Referenzbereiche haben (...) (s.v. Falsche Freunde). Outro tanto acontece com CRYSTAL (1994): Words in different languages which resemble each other in form, but which express different meaning (...) (s.v. false friend). Finalmente, citamos também BUßMANN (1990): (...) Paare von Worten aus verschiedenen Sprachen, die trotz ähnlicher Form verschiedene Bedeutung haben (...) (s.v. faux amis). Naturalmente, poderia-se objetar que as definições que temos apresentado pertencem à primeira metalíngua. No entanto, um sistema conceitual opera no nível da segunda metalíngua. Porém, consideramos que há dois fatores que devem ser levados em conta: primei-

\footnotetext{
${ }^{11}$ Nossa definição se baseia nos manuais e gramáticas indicadas ao lado de cada designação. Para uma visão de conjunto cfr. SECO (1998, s.v. pretérito indefinido). Pode-se constatar também que NEBRIJA (1492 [1992, fo 58v.) não errou ao falar de "passado acabado".

${ }^{12}$ Estamos cientes que neste caso se cumpre a regra básica de toda nomenclatura, isto é que la nomenclature supposse la biunivocité du rapport signifiant-signifié: um seul nom por chaque chose (...) (DUBOIS et alii, 1999, s.v. nomenclature). De outra parte, constatamos que tal ideal não sempre se cumpre na prática, como revelam os exemplos da gramática espanhola.

${ }^{13}$ Em relação à designação do conteúdo sêmico, temos acolhido a proposta de BALDINGER (1977, p.163), quem destingue entre significação (um conteúdo sêmico ligado a um significante) e significado (conjunto de todas as significações ligadas a um significante).
}

186 
ramente, que todo dicionário de lingüística é "per se" um dicionário que dá conta de uma única língua funcional (=linguagem técnica, neste caso), na qual, segundo COSERIU (1980, p. 104), os significados coincidem com as designações (no sentido de serem objetivamente motivados). Por outro lado, desde uma perspectiva jakobsoniana, se poderia argumentar, também, que a função metalingüística não implica somente em verbalizar a própria linguagem, mas, por meio dessa operação de se "auto enxergar", a linguagem ordena a linguagem. Portanto, existe também, ainda que não com a sistematicidade de um Begriffsystem, uma classificação do Sprachgutes.

Tendo em vista aos argumentos já expostos é que acreditamos que as definições citadas "ad supra" constituem também a definição conceitual do fenômeno léxico de que estamos tratando.

O problema, porém, são as designações que se tem dado ao dito fenômeno. Elas são, na nossa opinião, confusas e inexatas. A esse respeito, WÜSTER (1991) tem manifestado que es empfiehlt sich, Benennungen zu suchen und zu benutzen, die nicht (...) mißverstanden werden können (p. 72). A nossa rejeição a quase todas elas parte justamente desse fato, isto é, que quase todas são ambíguas.

OS VARIOS (E ERRÔNEOS) NOMES PARA UM MESMO FENÔMENO

Na continuação oferecemos uma listagem de designações para o fenômeno léxico contrastivo que analisamos na oportunidade: falsos cognatos (ALTROCCHI, 1935) ${ }^{14}$, heterossemânticos (SANTOS SILVA, 1992) ${ }^{15}$, homônimos interlinguales (WANDRUSZKA, 1977), falsos enganadores (POLITZER, STAUBACH, 1965) ${ }^{16}$, ou falsos amigos (KOESSLER, DEROCQUIGNY, 1928). A esse respeito, ÁLVAREZ (1997) manifesta que [se trata de] unha terminoloxia vacilante consecuencia duns conceptos pouco claros (p.44). Na nossa opinião, voltamos a insistir, não é o caso de uma definição conceitual pouco clara, mas de designações ambíguas.

Temos visto que a definição conceitual está suficientemente fixa e bem delimitada. As designações para essa definição, porém, não são neutras. O caso dos falsos amigos não é o único fenômeno onde isso acontece:

${ }^{14}$ Apud MASCHERPE,ZAMARIM (1998, p. 9).Quando não temos tido acesso direto a uma fonte bibliográfica, fornecemos a referência do texto onde ela aparece mencionada.

${ }^{15}$ Apud ÁlVAREZ (1997, p. 44).

${ }^{16}$ Apud DURÃO (1999, p. 142). 
Alguns lingüistas alemães, por exemplo, procuraram substituir Dialektgeographie por Areallinguistik, tentativa que não teve sucesso. Nosso objetivo será, portanto, julgar uma a uma as tais designações, mostrando como elas, ainda que aparentemente simples etiquetas, afetam a percepção desse fenômeno léxico.

Uma boa designação não pode constituir uma "contradictio in terminis", ou, para falar em alemão, ela não pode ser "irreführend". $\mathrm{Na}$ nossa opinião, o importante é que a(s) designação(ões) seja(m) clara(s) e distinta(s), no sentido da lógica. Adiante analisaremos e discutiremos as designações empregadas para esse fato léxico.

Uma das mais usadas é a de falsos cognatos. Em BUGUEÑO (1999, p.74 e ss.) temos argumentado contra tal designação. De uma parte, consideramos que a palavra cognato restringe demsiadamente o problema. Lembramos que cognato se refere a uma língua ou forma lingüística historicamente derivada da mesma fonte de outra língua/forma (CRYSTAL, 1988, s.v. cognato). Ou seja, existiria o fenômeno léxico que nos preocupa nesta ocasião somente naqueles casos em que há uma relação etimológica ${ }^{17}$ entre duas formas. Falsos cognatos seriam, por conseqüência, aqueles casos em que o critério subjacente de comparação é sempre o caso de um "tertium comparationis", ainda que a base de comparação etimológica evidencie uma discrepância sêmica. Em síntese, segundo esse critério, não se poderia considerar nenhum par de palavras de duas línguas que não tivessem uma relação etimológica. Em BUGUEÑO (1999, ibid.) temos fornecido abundantes exemplos sobre esse particular. Basta citar aqui outro caso paradigmático: MASCHERPE, ZAMARIM (1998) escolheram essa designação para o seu dicionário. Se atermos, "stricto sensu" à condição antes dada, então verbetes tais como ingl. jest $(<$ lat. gesta)/port. gesto $(<$ lat. gestus), ingl. race ( $<$ ingl. ant. raes)/port. raza (<lat. ratio) ou ingl. rest $\left(<\right.$ ant.alt.al. ruorra)/port. resto $(<\text { lat. restare })^{18}$ não poderiam aparecer na nominata, já que as etimologias para cada par léxico são diferentes ${ }^{19}$. Outro exemplo clássico é o caso de it. burro/esp. burro, que apresentam duas bases etimológicas completamente distintas ${ }^{20}$.

${ }^{17}$ Por exemplo, para GORBAHM-ORME, HAUSMANN (1991, p.2883) não se poderia falar desse fato léxico se não existe uma forma etimológica comum.

${ }^{18}$ As etimologias respectivas têm sido tomadas de WEBSTER'S COLLEGIATE (1999), para o inglês, e CUNHA (1996) para o português.

${ }^{19}$ Dentre os teóricos GAUGER (1982, p. 78-79) destaca também esse fato. Nesse sentido não podemos desconsiderar o que WANDRUSZKA (1977, p. 58) chama de spielerische $(r)$ Zufall e que explica por que não recomendável considerar somente os pares com uma mesma base etimológica.

${ }^{20}$ It. burro "manteiga" (<lat. but'rum id.), cfr. PIANIGIANI (1990,s.v. burro)/esp. burro (<forma regressiva de borrico, lat, tardio burricus "cavalo pequeno"), cfr. COROMINAS (1987, s.v. borrico). 
Outra designação que vem ganhando destaque aqui no Brasil é a de heterossemânticos. Se a designação deve dar conta de um fato lingüístico claro e definido, que se oponha a outros fatos lingüísticos, então heterossemânticos é altamente insatisfatória, já que parece que a "pluralidade na semanticidade" de uma palavra ocorre somente no fenômeno léxico de que tratamos, coisa que é, naturalmente, completamente absurda. Heterossemânticos, por outra parte, está associado a heterossemia, que, segundo METZLER (2000) significa Bedeutungsverschiedenheit vom Lexem im Falle der Homophonie, Homographie und Homonymie (s.v. Heterosemie). Em outras palavras, heterossemanticidade seria mais bem outra designação para polissemia.

A designação homomorfos heterosemânticos tampouco é completamente satisfatória, devido à confusão que gera. Ao se falar em palavras que têm a mesma estrutura fonológica, mas diferente significação, onde é que fica a diferença entre o fenômeno léxico contrastivo que nos preocupa e a homonímia e/ou polissemia ${ }^{21}$ ? Assim, por exemplo, ao interior do par léxico esp. acordar/port. acordar se dá a seguinte situação: esp. acordar é homofônico (cfr. COROMINAS, 1987, s.v. acordar ${ }^{1}$, acordar ${ }^{2}$ ), ou seja, cumpre, segundo ÁLVAREZ (1997,ibid.), a condição de ser homomorfo heterossemântico. De outro lado, entre esp. acordar/port. acordar existem significações não compartilhadas. São, portanto, também homomorfos heterossemânticos. Como estabelecer a diferença entre um e outro fenômeno léxico a partir da mesma designação?

Em relação à falsos enganadores, parece ser o caso clássico de "contradictio in terminis". Se um falante do espanhol manifesta em português que uma iguaria é exquisita (na significação esp. "gostosa"), então a condição de igualdade fonológica entre port. exquisito e esp. exquisito o terá enganado efetivamente. O que seria então, um falso enganador? Algo que, aparentemente, engana mas não engana?

Uma solução um tanto diferente é a que propõe WANDRUSZKA (1977,ibid.) com a designação homônimos interlinguales. Ainda que não oferece, na nossa opinião, uma solução completamente satisfatória, pelo menos, faz alguma justiça à realidade lingüística, pois se está reconhecendo o caráter contrastivo do fenômeno que envolve duas línguas.

Para o final deixamos a designação que, na nossa opinião, é a menos complicada. Falsos amigos parece uma designação menos "séria e

${ }^{21}$ Temos sido particularme cuidadosos no uso alternativo dos conectores aditivo e disjuntivo na nossa formulação, seguindo a observação e PALMER (1991): it is not always clear wheather we shall say that [sc. a pair of words are] an example of polisemy (...) or of homonimy (...) (p.101). Optamos pela alternativa da homonimia em razão de critérios etimológicos. 
científica", mas como já assinalamos em outra oportunidade (BUGUEÑO 1999, p. 75), é mais bildhaftig e não gera as confusões das outras que temos analisado. De uma parte, temos que reconhecer que o seu valor metafórico é grande, já que a cada vez que encontramos uma palavra em uma língua estrangeira que, efetivamente, é igual ou parecida a uma da nossa língua materna (ou de outra que conheçamos), temos a tendência a lhe conferir a mesma significação, independentemente se as significações entre uma e outra palavra coincidam ou não. Assim, por exemplo, quando se traduz se tende automaticamente a estabelecer tal relação $0^{22}$. Desta forma, a aparente ajuda que significa encontrar uma palavra conhecida, "amiga" em uma outra língua, vira uma ajuda enganosa quando as significações não coincidem plenamente. Essa palavra é, então, uma "falsa amiga". De outra parte, ainda que de caráter tão coloquial, a designação falsos amigos se tem convertido em uma expressão bem aceita entre os lingüistas, sem que, porém, tenha logrado afastar as demais.

\section{BIBLIOGRAFIA}

ALMEIDA, Gladis Maria de Barcellos. A problemática epistemológica em terminologia:Relação entre conceitos. Alfa, São Paulo, v. 42, p. 223233, 1998.

ÁLVAREZ, Alberto. Os falsos amigos da tradución. Criterios de estudio e da clasificación. Vigo, Servicio de publicaciones de la Universidad de Vigo, 1997.

BALDINGER, Kurt. Teoría semántica.Hacia una semántica moderna. Madrid, Ed. Alcalá, 1977 (2a.ed.).

BELLO, Andrés. Gramática de la lengua castellana. Madrid, EDAF, 1846 [1984].

BUGUEÑO, Félix. Cuán falsos (algunos) amigos! Artexto, Rio Grande, v. 10, p.73-84, 1999.

. A propósito dos dicionários de 'falsos amigos': 'Kritische Würdigung' de Hundertmark-Santos Martins 1995. Expressão, Santa Maria v.4 n.1. p. 123-128, 2000a.

. Cuán sexista puede ser realmente el lenguaje? La hipótesis de SapirWhorf y la lingüística femenina. Artexto, Rio Grande, v. 11, p. 99-116, $2000 \mathrm{~b}$.

${ }^{22}$ É bom lembrar que KOESSLER, DEROCQUIGNY (1928) “inventaram” a designação faux amis pensando justamente na atividade da trudução.

190 
- Resenha crítica a Bredemeier et alii. 1997. Expressão, Santa Maria, v.4 n 2., p. 210-211, 2000c.

- Sobre el español del siglo XVI. Caligrama, Belo Horizonte, v. 5, p.73-99, 2000d.

BUßMANN, Hadumod. Lexikon der Sprachwissenschaft. Stuttgart, Kröner, 1990 (2a.ed.).

COROMINAS, Joan. Breve diccionario etimológico de la lengua castellana. Gredos, Madrid, 1987 (3a.ed.).

COSERIU, Eugenio. A língua funcional. In:Lições de lingüistica geral. Rio de Janeiro, Ao Livro Técnico, 1980.

CRYSTAL, David. Dicionário de lingüística e fonética. Rio de Janeiro, Jorge Zahar, 1988.

. An encyclopedic dictionary of language and linguistics. London, Pinguin Books, 1994.

CUNHA, Antônio Geraldo da. Dicionário etimológico Nova Fronteira da lingua portuguesa. Rio de Janeiro: Nova Fronteira, 1996 (2a.ed.).

DUBOIS, Jean et alii. Dictionnaire de linguistique et des sciences du langage. Paris, Larousse, 1999.

DURÃO, Adja Balbino de Amorim Barbieri. Análisis de errores e interlengua de brasileños aprendices de español y de españoles aprendices de portugués. Londrina, Ed. UEL, 1999.

ESBOZO. Real Academia Española. Esbozo de una nueva gramática de la lengua española. Madrid, Espasa-Calpe, 1973.

GAUGER, Hans-Martin. Falsche Freunde. In: WUNDERLI, Peter, MÜLLER, Wulf (Hrsgn.). Romania historica et Romania hodierna:Festschrift für Olaf Deutschmann zum 70.Geburstag. Frankfurt am Main-Bern, Peter Lang, 1982.

GILI GAYA, Samuel. Curso superior de sintaxis española. Barcelona, Bibliograf, 1979 (12a.ed.).

GORBAHN-ORME, Adeline, HAUSMANN, Franz Joseph. The dictionary of False Friends. In:HAUSMANN, Franz Joseph et alii. Wörterbücher, Dictionaries, Dictionnaires:Ein internationales Handbuch zur Lexikographie III.Berlin, New York, Walter de Gruyter, 1991.

GRAMÁTICA. Real Academia Española. Gramática de la lengua española, Madrid, Espasa-Calpe, 1931.

HALLIG, Rudolf, WARTBURG, Walter von. Begriffsystem als Grundlage für die Lexikographie.Versuch eines Ordnungsschemas. Berlin, Akademie Verlag, 1963 (2a.ed.). 
HEGER, Klaus. Die methodologischen Vorraussetzungen von Onomasiologie und begrifflicher Gliederung. Zeitschrift für romanische Philologie, Tübingen, v. 80, p. 486-516, 1964.

HOMBURGER, Louis. Le langage et les langues. Paris, Payot, 1951.

KOESSLER, Maxime, DEROCQUIGNY, Jules. Les faux amis des vocabulaire anglais et américain. Conseils aux traducteurs. Paris, 1928.

MASCHERPE, Mário, ZAMARIN, Laura. Os falsos cognatos na tradução do inglês para o português. Rio de Janeiro, Bertrand Brasil, 1998 (6a.ed.).

METZLER. Metzler Lexikon Sprache, hrsg. von Helmut Glück, Stuttgart, J.B. Metzler, 2000.

NEBRIJA, Elio Antonio de. Gramática castellana. Madrid, Fundación Antonio de Nebrija, 1492 [1992]

PALMER, F.R. Semantics. Cambridge, Cambridge University Press, 1991 (2a.ed.).

PIANIGIANI, Ottorino. Vocabolario etimologico della lingua italiana.La Spezia, Fratelli Melita, 1990 (3a.ed.).

REY, Alain. La terminologie.Noms et notions. Paris, PUF, 1979.

SECO, Manuel. Diccionario de dudas y dificultades de la lengua española. Madrid, Espasa-Calpe, 1988 (9a.ed.).

VERNAY, Henri. Dictionnaire onomasiologique des langes romanes. Tübingen, Max Niemayer 1991 passim.

WANDRUSZKA, Mario. "Falsche Freunde": ein linguistisches Problem und seine Lösung. In: LEITENBERGER, Hugo (Hrsg.). Festgabe für Julius Wilhelm zum 80. Geburstag. Wiesbaden, Franz Steiner, 1977.

WEBSTER'S COLLEGIATE. Merriam Webster's collegiate dictionary.Springfield, Merriam Webster's 1999 (10 ${ }^{\text {th }}$ ed.).

WÜSTER, Eugen. Einführung in die allgemeine Terminologielehre und terminologische Lexikographie. Bonn, Romanistischer Verlag, 1991 (3a.ed.). 